Article

\title{
Navigating Onlife Privacy: A Family Environment Perspective on Children's Moral Principles
}

\author{
Joke Bauwens ${ }^{1, *}$, Katleen Gabriels ${ }^{2}$ and Lien Mostmans ${ }^{3}$ \\ ${ }^{1}$ CEMESO, Vrije Universiteit Brussel, 1050 Brussels, Belgium; E-Mail: joke.bauwens@vub.be \\ 2 Department of Philosophy, Maastricht University, 6200 MD Maastricht, The Netherlands; \\ E-Mail: k.gabriels@maastrichtuniversity.nl \\ ${ }^{3}$ Office of Research and Innovation, Erasmus Brussels University of Applied Sciences and Arts, 1070 Brussels, Belgium; \\ E-Mail: lien.mostmans@ehb.be \\ * Corresponding author
}

Submitted: 22 May 2020 | Accepted: 4 September 2020 | Published: 10 November 2020

\begin{abstract}
This article illuminates which moral principles children and their parents invoke to explain onlife privacy-related practices from a family ecological and narrative approach. It draws on a focused ethnographic study with 10 Flemish socially privileged families with a keen interest in digital technologies and at least one child entering their teenage years. We analyse our data through the analytical lens of a sociopsychological framework that considers children's privacy experiences from three dimensions: self-ego, environmental, and interpersonal. Overall, this article concludes that while risk-averse concerns are present in both the parents' and children's narratives about onlife privacy, parents have allowed their maturing children considerable privacy and leeway. Also, both parents and children articulated the importance of respecting one another's privacy. We frame this set of principles as 'quadruple R': responsibility, risk, reputation, and respect for privacy.
\end{abstract}

\section{Keywords}

children; emerging teenagers; family environment; morality; onlife; privacy

\section{Issue}

This article is part of the issue "Children's Voices on Privacy Management and Data Responsibilization" edited by Ralf De Wolf (Ghent University, Belgium) and Mariek Vanden Abeele (Tilburg University, The Netherlands).

(C) 2020 by the authors; licensee Cogitatio (Lisbon, Portugal). This article is licensed under a Creative Commons Attribution 4.0 International License (CC BY).

\section{Introduction}

Drawing on the plethora of data on teenagers' online privacy practices, on the one hand, and digital parenting, on the other, one cannot but conclude that privacy evokes a wide range of moral considerations (Blum-Ross \& Livingstone, 2017; Flores \& James, 2013). Our inquiry starts from this observation and argues, in line with others (Jorge \& Farrugia, 2017), that in order to understand actual privacy behaviours, the "underlying moral logics in young people's accounts of their practices" (Berriman \& Thomson, 2014, p. 583) warrant more in-depth research. Given that family plays a major role in how children and young people learn to deal with media and life
(Clark, 2013; Paus-Hasebrink, Kulterer, \& Sinner, 2019), this article proposes a context-sensitive ecological perspective, exploring the interaction between families' privacy practices, which are inherently moral, and children's "as both developing beings and active moral agents" (Montreuil, Noronha, Floriani, \& Carnevale, 2018, p. 25). We will speak about 'onlife' privacy, emphasising that "the physical and the digital are not separate realms, but jointly part and parcel of the human condition" (Koops, 2018, p. 654).

In doing so, we build on qualitative data that were collected for the PhD study of one of this article's authors (Mostmans, 2017). The research included 10 Flemish socially privileged families with a keen interest in dig- 
ital technologies. In these families at least one child had just made the transfer from junior to senior school and was about to hit puberty or had just entered his teens; so-called "emerging teenagers" (Paus-Hasebrink et al., 2019, p. 53). From other studies, we know that these families offer an interesting scene for inquiring privacy and the surrounding moral negotiation. With children striving for more autonomy and intense digital media use, these families are increasingly confronted with various turning points, lively debate, unease and concern, also regarding privacy (Kaare, Brandtzaeg, Heim, \& Endestad, 2007).

This article aims to contextualise the set of principles children and parents in these families use to navigate onlife privacy. We draw upon a somewhat forgotten, but remarkably topical interdisciplinary framework developed in the 1970s by Wolfe along with her colleagues Laufer and Proshansky, for analysing the different dimensions of privacy in the family context. We bring these dimensions into dialogue with recent studies on how both parents and children enact morality regarding privacy and the Internet.

The first part of the article starts with defining morality, addressing the family as the primary, secure setting for moral socialisation and discussing how emergent teenagers affect the private-public dynamics within families. We then shed light on the three dimensions of privacy, as proposed in the aforementioned analytical framework, and the four key principles that have become apparent in recent studies on young people's narratives of Internet experiences. In the second part, the methodology is explained. The third part unfolds the findings of the study organised along the three dimensions and key moral principles children and their parents fall back on to justify their practices. Overall, we underline the importance of the quadruple $\mathrm{R}$ framework within this particular social milieu as a set of moral principles to orient one's own behaviour and interpret that of others.

\section{Theoretical Background}

\subsection{Morality in Family Context}

Morality can be defined as a person's negotiation with the values and beliefs that are displayed within a shared culture, community, or group. On an individual level, morality is about evaluating one's own and other's behaviour, principles, judgment, norms, and values. On a social level, morality ties us all to each other and makes it possible to fulfil our strong need to be part of a group. Moral experience, development, and agency are shaped by interpersonal interactions and group involvement (Haidt, 2003; Hitlin \& Vaisey, 2010).

Everyday family life is the primary realm of moral experience. It is where morality is recurrently practised, values are learned and tested, and beliefs are given and challenged. Academic literature shows that parents serve as models of morality-in terms of setting the example-for their children (Steinberg \& Silk, 2002). Everyday family life "is imbued with implicit and explicit messages about right and wrong, better and worse, rules, norms, obligations, duties, etiquette, moral reasoning, virtue, character, and other dimensions of how to lead a moral life" (Ochs \& Kremer-Sadlik, 2007, p. 5). Discursive approaches to morality have demonstrated that moral norms are constantly negotiated and enacted in family interactions (Sterponi, 2003). In narrative psychology, everyday interactions among parents and children are viewed as a key component in the formation of the moral self, for both parties (Pasupathi \& Wainryb, 2010). Therefore, what we call morality includes how both children and parents explain, give meaning to, and construct narratives about privacy.

In particular with emergent teenagers who seek to gain autonomy in developing a personal identity, it is fairly common that families have to deal with conflicting perceptions of the moral values surrounding privacy. As children enter adolescence, they gain more independence and aloneness, explore tactics to avoid parental control, negotiate rules with their parents, and see their opportunities for unsupervised interaction with others proliferating, both online and offline, such as on their way to school (boyd, 2014; Zimmer-Gembeck \& Collins, 2003). They seek more privacy, for instance in their rooms or by hiding information from their parents, as they hold on to the increasing importance of secrecy (Kaare et al., 2007; Livingstone \& Sefton-Green, 2016). A wide spectrum of media practices, such as listening to music, having one's own smartphone, gaming, interacting on social media, accompany this process (Ortner \& Holly, 2019). Teenagers use online media, and in particular social media, "to show to peers that they grew out of childhood" (Balleys \& Coll, 2017, p. 887). That makes it more difficult for parents to keep up with their children's engagement with the media and, essentially, with others. Especially teenagers' commitment to peer culture, enacted through intensive online interaction, can accelerate processes of distancing in the family (Kaare et al., 2007). Recent studies, however, show that parents are still seen as the source of inspiration and values and families as the beacon of moral guidance (Girsh, 2014; Jorge \& Farrugia, 2017).

\subsection{A Three-Dimensional Definition of Privacy}

Contemporary scholarly work on both digital childhood and children's morality converges on the position that children are participants in their own right who are capable of understanding and experiencing life, but that this cannot be divorced from the sociocultural contexts in which they grow up (Frankel, 2012). The establishment of a child-oriented and ecological approach to privacy can be traced back to Wolfe along with her colleagues (Laufer \& Wolfe, 1977; Wolfe, 1978). In their pioneering work, the North American scholars start from a child-centred perspective that stresses the equal importance of "age 
and age-related experiences" (typically a psychological concern) and the role played by "cultural and sociophysical environmental factors" (a traditionally sociological concern; Wolfe, 1978, p. 175). In more recent scholarly work on childhood, media, socialisation, and development, exactly this dynamic interplay of individual and structural components has become key in understanding children's dealings with digitally networked devices (Paus-Hasebrink et al., 2019). The framework thus provides a good starting point to analyse how emerging teenagers' concepts of privacy are tied to concrete situations in everyday life.

The framework points to three interacting dimensions that shape how young people conceptualise and experience privacy and privacy infringement. It accentuates that these three dimensions are dynamic throughout time and history. Hence, the way people (not only children) alter as they progress through the life cycle influences how they perceive and define privacy. However, larger sociohistorical transformations also outline the paradigms for people's thoughts on childhood, adulthood, parenting, and privacy. Furthermore, the framework acknowledges that the three dimensions are differential across various cultural and social contexts.

First, there is the self-ego dimension of privacy. It shows that the psychological aspects of privacy, such as protecting, nurturing, and enhancing the self, and the possibility of separateness, being and functioning alone, are intrinsically connected with moral values such as personal dignity, freedom to choose your own movement, personal agency for control, and choice over with whom one's personal information is shared (Burkell, 2016). Although not widely accepted, the relationship between respect for children's individuality, privacy, and well-being is a cornerstone in the 2007 World Health Organisation's framework of good parenting and a child's right (cf. United Nations General Assembly, 1989, Art. 16). In Flanders, where this study's data were gathered, The Office of Children's Rights Commissioner, founded in 1997 , is active in ensuring this.

This brings us to the second, so-called environmental dimension that shapes which privacy options young people have at their disposal. Here, cultural meanings about privacy, such as mores of a community, cultural meanings, tradition, values, lifestyle, and history play an important role (Laufer \& Wolfe, 1977, p. 24). The authors point out that especially culture, which includes cultural imageries about good parenting, family life, or childhood, is a decisive and robust environmental element. Likewise, the interaction between social and physical aspects of environments deserves attention. For example, social arrangements, family composition, types of tasks required (such as studying, working) and rituals (such as family meal, bedtime) circumscribe the available options on which young people are dependent and from which they can draw to give meaning to privacy. These are entangled with physical characteristics of places (such as design, available technologies, and the physical presence of people). Clearly, since then, the public-private boundaries of the family home have changed drastically, not the least with online media. It has become more difficult to prevent the outside world from entering the home, and vice versa-the privacy of the home is easily shared with distant others. Hence, the home and family, typically seen as one of the key private spaces, faces the complexities of interactions stretching out over online and offline contexts (Koops, 2018).

This leads us to the third so-called interpersonal dimension of privacy. This dimension has attracted a dominant focus in scholarly work on young people and online privacy (see for example Zarouali, Poels, Walrave, \& Ponnet, 2019). It deals with questions such as what information children choose to share with others about themselves and how they try to learn to be in control of that (e.g., disclosure of personal information). This requires management on a daily basis and produces conflicts with others and with oneself, especially for young people who often face situations that are controlled by adults and technologies. However, childoriented research indicates that self-disclosure behaviour of young people, often deplored by adults, is a key component in strengthening social ties among peers. By eliciting and providing feedback, support and empathy from and to others, young people construct and explore morality, in terms of belonging, community, the relationship between the self and the other, etc. (Balleys \& Coll, 2017; Mostmans, 2017). On the other hand, as their social life is expanding and their moral agency is developing, young people also struggle with finding a balance between the boundaries of online peer groups and personal boundaries (Adorjan \& Ricciardelli, 2019).

\subsection{Privacy and Morality: The Quadruple R Principles}

Notwithstanding the popular image of teenagers' rashness in online privacy matters, studies from the recent past increasingly show that young people care deeply what they want to share about themselves with others (Balleys \& Coll, 2017). This sensitivity seems to resonate with the amount and tone of media coverage on online privacy (De Wolf \& Joye, 2019) and increasing attention to digital media literacy in education (Pangrazio \& Cardozo Gaibisso, 2020). From research on digital parenting, we learn that parents too are sensitive to their children's privacy, not only in terms of protecting their children from malicious intrusion (e.g., predators, harassment) and commercial exploitation (e.g., advertising, tracking, dataveillance), but also in their relationship with their children (Blum-Ross \& Livingstone, 2017). Together, these studies seem to suggest that both children and parents mobilise four key categories to orient their conduct and the interpretation of others' conduct, namely: risk, responsibility, reputation, and respect; coined as the quadruple $\mathrm{R}$ principles.

First, among children, risk awareness is an important moral compass to fend off dubious digital activi- 
ties (Adorjan \& Ricciardelli, 2019; Berriman \& Thomson, 2014). Parents also continue to frame their concerns about their children's online interactions within the wider cultural imaginaries of stranger danger, in which media coverage plays a magnifying role (Drotner, 2013; Leick, 2019).

Second, young people are increasingly encouraged to rely on their sense of responsibility. Stimulating selfreliance is quite common in socially diverse, busy families with teenagers, where moral rules are not always clearly defined and sanctions are rather limited (Frankel, 2012; Livingstone \& Sefton-Green, 2016). In turn, emergent teenagers blame peers who experience negative side effects of revealing too much personal information of not being savvy enough or of being vain attentionseekers (Jorge \& Farrugia, 2017).

Third, conscious of the potential consequences that their digital performances can have on their reputation, young people demonstrate prudence, both online and offline (Adorjan \& Ricciardelli, 2019). Girls are especially sensitive to how their online performances might be received and run the gauntlet of decency by navigating the social and moral complexities of whether or not to share sexually suggestive images of themselves (Ringrose \& Harvey, 2015). Parents as well are concerned about the reputational damage of children's online representation (Autenrieth, 2018).

Fourth, maturing children increasingly attach great importance to how other people respect their privacy and take offence at adults (parents specifically) snooping in their personal space and sharing uneasy details about children's personal life online (Lupton \& Williamson, 2017). In one of our studies, we found that from the age of nine, children morally disapprove of parents disclosing information about their children without consent (Mostmans, Bauwens, \& Pierson, 2014).

\section{The Study: Sample, Data Collection, and Analysis}

In the study at hand, a focused ethnographic research approach was used (Knoblauch, 2005). Unlike conventional ethnographic work, it focuses on a particular aspect of people's daily life and is characterised by short-term field visits, intensive use of audio-visual technologies of data collection and more delineated time spent in the field (in part-time rather than a permanent researcher presence). The field work was carried out throughout 2013-2015 in Flanders, the Dutch-speaking part of Belgium. The sample consisted of 10 families with at least one child aged 10-14 years living in urban and suburban areas. Although the families varied in terms of family type and composition, all parents shared a keen interest in digital technologies (see Table 1). Some of the parents were tech workers or worked in communications, with advanced media proficiency (Michael Daniels, Julia Philips, Peter and Jill Meyer, Fred Stevens, Daniel Stokman). Others, such as the Bissettes and the Salomons, could be described as 'geeky' families "where digital activities and play are a source of shared enjoyment and learning" (Livingstone \& Blum-Ross, 2019, p. 70). The rest of the families balanced between technology-enthused and averse but were nonetheless convinced of the importance of digital media for education, work, society, economy, etc. (the Arnolds family, the Jacobs family, the Mansour family). Overall, the 10 families scored high in terms of educational level or income, and in certain cases, in both areas (see Table 1).

We used different methods of data gathering to contextualise the family's narratives about digital media and privacy. First, through participant observations, we were able to: find out how and where the children used media devices; observe explicit and implicit family (spousal, sibling, parent-child) interactions; make reflective notes on how parents and children communicated with each other about or through media; observe the Internet activities of the children; and audio-record relevant spontaneous talk. For example, we asked them about their recent online activities and experiences (e.g., What did you post online this week, and why? Did you see or experience anything special?), and to take us on a 'digital tour' around their personal and preferred pages. The children led the tours, explaining what they had posted, what they found interesting and fun, and what they did not like so much.

Second, the participant observations formed the starting point of individual ethnographic interviews (with parents and children separately) and group ethnographic interviews (with the family) in the homes of the families. Given our interest in families' narratives, the focus shifted from "what actually happened" to "how people make sense of what happened" (Bryman, 2012, p. 582). During one of the visits, parents and other caretakers were invited to recall how they had experienced privacy as a child. Parents constructed their life story as a reflexive narrative which allowed us to grasp the moral values they believed to be critical and how they came into play in their relationship with their children. While the individual interviews enlightened us about the individual experiences of the children and parents, the group interviews illuminated how a family collectively made sense of onlife privacy. We explained that the interviews could take place anywhere in the house where they felt most comfortable. The majority of interviews took place in the living room or, with some families, in the children's bedrooms. Lastly, to encourage the children's involvement, we used various participatory methods, such as categorising vignettes that described online privacy-related rules and situations; mapping the family's home environment in terms of media devices and public-private boundaries (see Figure 1).

Specifically, the analysis of all data for each family was clustered along two axes. One axis used the three privacy dimensions which functioned as analytical constructs for identifying when, how, and where privacy-related experiences mobilised moral reflection 
Table 1. Overview of families.

\begin{tabular}{|c|c|c|c|}
\hline & & dontolo & Social milieu \\
\hline $\begin{array}{l}\text { Family 1: } \\
\text { Arnolds }\end{array}$ & Nuclear family & $\begin{array}{l}\text { Steve (father), Jane (mother), } \\
\text { Tom (male, 12), Alex (male, 10) }\end{array}$ & $\begin{array}{l}\text { Steve, administrator } \\
\text { Jane, administrator } \\
\text { Double income } \\
\text { High income }\end{array}$ \\
\hline $\begin{array}{l}\text { Family 2: } \\
\text { Bissette }\end{array}$ & Nuclear family & $\begin{array}{l}\text { David (father), Vicky (mother), } \\
\text { Sophie (female, 13), } \\
\text { Anthony (male, 10) }\end{array}$ & $\begin{array}{l}\text { David, museum worker } \\
\text { Vicky, administrator } \\
\text { Double income } \\
\text { High income }\end{array}$ \\
\hline $\begin{array}{l}\text { Family 3: } \\
\text { Daniels }\end{array}$ & Nuclear family & $\begin{array}{l}\text { Michael (father), Jessica (mother), } \\
\text { Kenny (male, age 13), Sam (male, 11) }\end{array}$ & $\begin{array}{l}\text { Michael, university degree, } \\
\text { IT engineer } \\
\text { Jessica, university degree, } \\
\text { IT engineer (in-between jobs) } \\
\text { Median income }\end{array}$ \\
\hline $\begin{array}{l}\text { Family 4: } \\
\text { Jacobs }\end{array}$ & $\begin{array}{l}\text { Divorced family, } 1 \\
\text { single-parent household } \\
\text { (Gemma was raising } \\
\text { Charlotte; father } \\
\text { occasionally came for visits) }\end{array}$ & $\begin{array}{l}\text { Gemma (mother), } \\
\text { Charlotte (female, 14) }\end{array}$ & $\begin{array}{l}\text { Gemma, teacher in primary } \\
\text { school } \\
\text { Stable median income }\end{array}$ \\
\hline $\begin{array}{l}\text { Family 5: } \\
\text { Mansour }\end{array}$ & $\begin{array}{l}\text { Divorced family, } 2 \\
\text { single-parent households } \\
\text { (Max' father, William, was } \\
\text { not part of the research) }\end{array}$ & Mina (mother), Max (male, 14) & $\begin{array}{l}\text { Mina, university degree, } \\
\text { freelance translator, writer } \\
\text { and part-time teacher } \\
\text { (looking for work) } \\
\text { Irregular income }\end{array}$ \\
\hline $\begin{array}{l}\text { Family 6: } \\
\text { Meyer }\end{array}$ & Nuclear family & $\begin{array}{l}\text { Peter (father), Jill (mother), } \\
\text { Eliza (female, 13), Ben (male, 11), } \\
\text { Charlie (female, 9) }\end{array}$ & $\begin{array}{l}\text { Peter, IT engineer } \\
\text { Jill, IT engineer } \\
\text { Highly educated } \\
\text { Double income } \\
\text { High income }\end{array}$ \\
\hline \multirow[t]{4}{*}{$\begin{array}{l}\text { Family 7: } \\
\text { Montgomery }\end{array}$} & Stepfamily, 3 households & $\begin{array}{l}\text { Denny (male, } 14 \text { ) lives in the Miller } \\
\text { and Phillips households (co-parenting } \\
\text { arrangement). } \\
\text { Vincent (male, 14) lives in the } \\
\text { Simmons and Phillips households } \\
\text { (co-parenting arrangement). }\end{array}$ & \\
\hline & & $\begin{array}{l}\text { The Phillips household: Walter } \\
\text { (Denny's father), Julia (Vincent's } \\
\text { mother), Kevin (Vincent's brother, 17, } \\
\text { not part of the research) }\end{array}$ & $\begin{array}{l}\text { Walter, executive in IT company } \\
\text { Julia, digital marketing manager } \\
\text { Double income } \\
\text { High income }\end{array}$ \\
\hline & & $\begin{array}{l}\text { The Simmons household: Robert } \\
\text { (Vincent's father, not part of the } \\
\text { research), Jennifer (Vincent's } \\
\text { stepmother), Anna (female, 9) }\end{array}$ & $\begin{array}{l}\text { Robert and Jennifer, } \\
\text { occupations not available } \\
\text { Double income } \\
\text { High income }\end{array}$ \\
\hline & & $\begin{array}{l}\text { The Miller household: Nancy (Denny's } \\
\text { mother), Simon (Denny's brother, 20, } \\
\text { not part of the research) }\end{array}$ & $\begin{array}{l}\text { Nancy, teacher in primary } \\
\text { school } \\
\text { Stable median income }\end{array}$ \\
\hline
\end{tabular}


Table 1. (Cont.) Overview of families.

\begin{tabular}{|c|c|c|c|}
\hline & & dontiones & Social milieu \\
\hline $\begin{array}{l}\text { Family 8: } \\
\text { Salomon }\end{array}$ & Nuclear family & $\begin{array}{l}\text { Oscar (father), Julie (mother), } \\
\text { Lucy (female, 16), Harry (male, 13), } \\
\text { Luke (male, 10), Trixy (female, 5, not } \\
\text { part of the research) }\end{array}$ & $\begin{array}{l}\text { Oscar, attorney and historian, } \\
\text { tech worker/creative worker } \\
\text { in a digital design agency } \\
\text { Julie, attorney; in between jobs } \\
\text { at the time of the study } \\
\text { Double income } \\
\text { High income }\end{array}$ \\
\hline $\begin{array}{l}\text { Family 9: } \\
\text { Stevens }\end{array}$ & Nuclear family & $\begin{array}{l}\text { Fred (father), Gina (mother), } \\
\text { Nathan (male, 13), Alexander } \\
\text { (male, 9), Ellie (female, 5, not part of } \\
\text { the research) }\end{array}$ & $\begin{array}{l}\text { Fred, director sales and } \\
\text { marketing in HR software } \\
\text { company, digital expert } \\
\text { Gina, teacher in secondary } \\
\text { school } \\
\text { Double income } \\
\text { High income }\end{array}$ \\
\hline $\begin{array}{l}\text { Family 10: } \\
\text { Stokman }\end{array}$ & Stepfamily, 2 households & $\begin{array}{l}\text { Daniel (father), Lisa (mother, not part } \\
\text { of the research), Rani (stepmother), } \\
\text { Daria (female, 10), Thomas (male, 9), } \\
\text { Lily (female, } 5 \text {, not part of the } \\
\text { research) }\end{array}$ & $\begin{array}{l}\text { Daniel, tech worker } \\
\text { Rani, communication officer in } \\
\text { IT research institute } \\
\text { Double income } \\
\text { High income }\end{array}$ \\
\hline
\end{tabular}

Note: All names used are pseudonyms. Both parents and children gave fully informed consent.

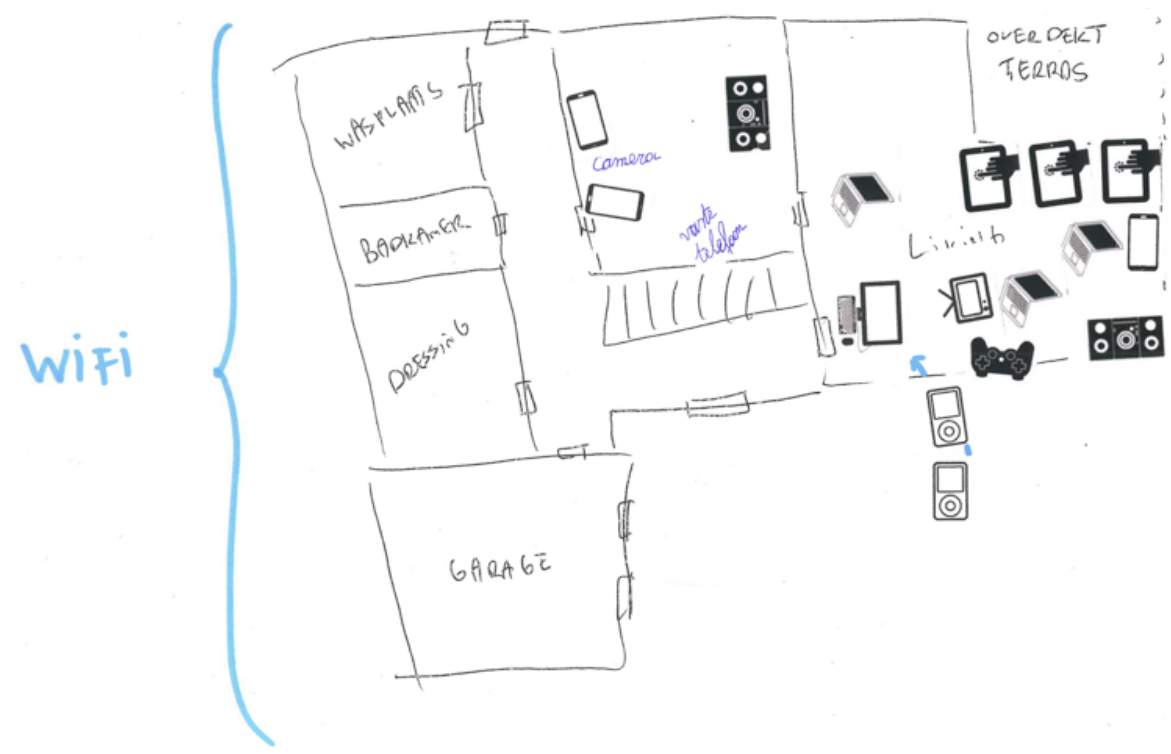

Figure 1. Example of a child's media use map.

and decision-making. The other axis used the quadruple $\mathrm{R}$ principles, as explained above, to analyse how and when parents and children invoked them. For example, the following excerpt would be coded as interpersonal and reputation:

We will regularly have a conversation about that, among others about time. I have talked with him,
I said, realise that if you write something somewhere that....You know, if you say something to someone, that is gone, but if you write something it remains visible. On the other side, it may also be read by parents. There were some lame comments, icons like turds and all those things, so it was not at all, how should I say it...shocking or so. But you know, you want to give a guideline....For example, on his mobile phone, he let 
me hear a sound recording of one of his friends farting, if I may say so. Yes, I understand that they are teenagers. But I wouldn't want him to do that to someone else, so these are things I try to talk to him about. (Gina, emphasis added)

In using data analysis software, we were able to obtain an integrated perspective on every single family as well as a comparative perspective on all families involved.

\section{Findings}

\subsection{Respect for Privacy as a Family Rule}

Overall, our findings show that privacy is an important value that manifests itself culturally and sociophysically. All parents acknowledged that privacy is a self-evident right, both for adults and children. Apart from Rani, stepmother in the Stokman family, all parents were born and grew up in Flemish families between the late 1960s and late 1980s. However, having been raised in families with different class backgrounds, parents sometimes had dissenting opinions about the boundaries of their own and their children's privacy and had to bring their divergent privacy experiences as children and teenagers in line with one another. Some of the parents recounted a strong sense of privacy in their families (e.g., not opening the mail of others; private bedrooms). Others grew up in families where they had little privacy. For some, this was accompanied by control and distrust by their parents. For example, Rani deplored the fact that she, as an adopted child with two strict parents of older age, was raised in an "overprotective" and "old-fashioned" household and had not enjoyed as much privacy as her peers in her youth. Oscar, the father in the Salomon family, mostly remembered his family's difficult relationship with secrecies; his father being a "closed book" and his "suspicious" mother "always wanting a thousand details." Others who had also experienced little privacy at home did not necessarily have unpleasant memories of their private experiences as a child. They reminisced about their family as a buffer of safety and trust, in which family members were open and transparent (e.g., no locks on the door).

Despite the variety of life stories, all parents presented privacy as a cornerstone of their child-rearing principles. For example, Rani was determined to do things differently with her stepchildren and stressed the idea that good parents "of our time" should respect their children's privacy and allow them some agency in choosing separation from their parents. In this sense, she actively sought to stimulate the children's self-reliance. Returning to the definition of privacy as outlined before, this and similar stories demonstrated how the cultural meanings surrounding privacy, in terms of values and norms, were widely shared within this social milieu.

In combination with most of the families' advantageous living conditions, the opportunities for both parents and children to retreat were plentiful. Apart from Max, all children grew up in spacious, single-family dwellings that offered many opportunities for privacy experiences. Most of the children had their own bedroom (at mother's and father's place if parents were separated), sometimes even their own floor or back house. Some children still shared their bedroom with a sibling but had the prospect of having their own bedroom when they would leave primary school. A wide array of shared devices (such as desktop computers, laptops, television), as well as individually used items (such as smartphones, game consoles, tablet computers, music players), was scattered across pretty much the whole house.

In the various types of family settings we investigated, we found that both parents and children used the potential of their living environment to produce privacy opportunities for themselves. Hence, not only did children report that they retreated into their bedroom or used earphones to create "unbothered" aloneness, parents also described how much they "needed to be on their own." The wish for separateness, typically ascribed to teenagers and problematised as a risk to the family's togetherness (Livingstone \& Sefton-Green, 2016), was thus also palpably articulated and practised by the parents. For instance, Mina, a single mother living with her son in a two-bedroom apartment, emphasised the importance of physical withdrawal at home. Other parents claimed the use of technological devices which allowed for psychological rather than physical withdrawal. Earphones proved to be important technologies to enable this kind of separateness. Parents also used these technologies to create "interactional boundaries" (Laufer \& Wolfe, 1977, p. 33) in rooms shared with their children.

Given that the children hardly ever recounted conflicts with their parents about privacy, it can be assumed that they felt indeed respected in their right to a certain amount of control and choice in their movements, interaction with others, and information needs. Overall, the children rarely expressed feelings of being in situations that heavily restricted the available forms of privacy in their family environment. Apart from disputes among siblings, sometimes even during the interviews, all children were relatively comfortable about how their family (or families, in the case of separated parents) engaged with their privacy.

\subsection{Exceptions to the Rule}

Especially with children entering their teenage years, parents expressed their desire for trust and rapport, encouraging their children to share their concerns and disturbing experiences, and at the same time allowing their maturing children privacy. Emotional involvement and trusteeship, often found in research on middle-class families and digital parenting (Livingstone \& Blum-Ross, 2019; Naab, 2018; Ortner \& Holly, 2019), were accompanied with a firm belief in children's empowerment and self-reliance. In particular parents-fathers mainly 
and some mothers who were apt consumers of digital media-articulated a deep sense of trust in their children's growing capabilities because of their own personal digital skills to which their children could resort. Overall, mothers displayed less digital self-confidence than fathers but told us that they worked hard to establish a trust relationship with their children. For example, Gina could not imagine how her three children would go about with privacy on the Internet in the near future, but was pretty hopeful that "they will just dare to tell or ask me and then we'll see when the moment is there."

Parents reported that they had invested a lot of effort into teaching their emergent teenager lessons about what to share with whom. For example, they typically used the momentum while creating a social media or game account for their children to talk about privacy and the rules they had to keep in mind. Most of all, parents stressed the importance of working towards open communication and trust. In such a family climate, parents showed a fair amount of trepidation about managing their children's online practices and distanced themselves, mainly mothers, from other mothers who had commented on their so-called "liberal" and "trusting" digital parenting style. For example, Jessica criticised these mothers "for not giving their children enough room to freely explore the Internet," while Gemma accused them of being "not sufficiently emotionally involved with their children, resulting in unpleasant privacy-related experiences."

Although the emergent teenagers were allowed considerable leeway, parental intervention in their privacy was consistently justified based on the same principles. In line with other studies, noted at the outset, concern about risk, responsibility, and reputation functioned as leads for explaining the onlife privacy rules at home. As long as parents intervened in line with these three entangled principles, teenagers would concur with that. For example, Walter instituted the practice of posting a message on his oldest daughter's Facebook timeline when she forgot to close her account after using his laptop. Since there was a heavy sense of taking responsibility for your online privacy in this family, Lucy did not interpret this as an invasion of her privacy by her father but as "her own fault."

But if privacy infringement by the parents could not be accounted for by these principles, emergent teenagers displayed great moral indignation. In the family Daniels, for instance, the oldest son had discovered via his history that his father had snooped into his logged-in Facebook account while working on the shared family computer. His younger brother was immediately on board and shared his brother's anger. So did the mother, who confronted her husband with this privacy intrusion. This incident was told by the mother with a mixture of embarrassment and indignation, as she saw it as a transgression of a clear family norm. She also found it difficult to reconcile the father's behaviour with the family's ideas about parenting which were firmly based on empowering their children by endorsing their self-confidence. Another incident concerned Denny. This boy, with separated parents, was heavily disappointed in his father who had checked private messages on his smartphone without his knowledge and contrasted his father's conduct with his mother's "great respect for his privacy."

\section{3. 'Keep Yourself and the Family Safe'}

Risk of privacy intrusion from outside the family was a main concern in the narratives the families relied on to give meaning to privacy. Interaction with unknown others was regularly mentioned as the first thing they would never do. Adult strangers were especially defined as not trustworthy to share personal information with. Parents pointed at the risk of predators and imprinted their children never to share personal details with unknown others. Daria re-enacted this rule in her own words as "people with bad intentions" and Denny as "people who might seek you out and harass you."

The families were also particularly occupied by the risk of burglary and parents had taught their children never to share online information about home addresses. Nonhuman actors, such as obscure games, shopping, and downloads, were also considered as potential privacy invaders. In this respect, "never disclose contact and banking details to unknown others" was regularly recited as a mantra. These children were raised with the idea that amidst an increasingly insecure and complex world, the family is your stronghold that helps you keep safe, but at the same time needs to be protected as well. Hence, children also were given a share of the responsibility to protect the family against intruders; they articulated a strong sense of co-responsibility in keeping their family safe. This sometimes meant that children did not tell their parents when they experienced privacy invasions on the Internet, fearing that their parents would have called into question their sense of duty, as Thomas explained to us.

\subsection{Care of the Self and Moral Superiority}

Reputation and one's task to watch over this were consistently linked with the self-ego dimension. Personal dignity was a repeated motif in the children's narratives. The emergent teenagers, who were allowed to go on social media when they entered secondary school, were especially conscious about what they would post online and what they would not. As demonstrated in many other studies, constructing 'a sense of self' has become increasingly a matter of digital performances and especially pictures. Parents also demonstrated concern about how they might be portrayed online; sometimes diverging in couples about the acceptability of photos, in terms of whether the other did not come out badly or was not ridiculed. Hence, protecting one's vulnerability and avoiding potential exposure to mockery and rejection 
were described as the main reasons why they would not share anything about themselves online. For instance, pictures in a swimming suit, asleep in bed, naked in the bath, naked tout court, were all examples of what they "would never share online."

Whereas the children's and parents' narratives on risk were mostly in unison, ideas about reputation could vary greatly. In this respect, the sharenting habits of parents in general and their own parents specifically were criticised. In the family Salomon, for instance, both parents were avid social media users and bloggers who regularly published pictures of their four children without their consent. The three oldest children took no offence in their parents' routine of talking about and sharing these pictures online. However, an old bathtub picture of the oldest daughter with her younger brother Harry as very young children was "unpalatable" from the daughter's viewpoint. The other son Luke was not pleased with a picture that his parents recently posted on Facebook of his brother and him fallen asleep together in the family's guest bed. The children showed sensitivity to embarrassing pictures that might be differently perceived by peers than parents.

Our findings also suggested that "moral judgements are genderised" (Jorge \& Farrugia, 2017, p. 286; see also Ringrose \& Harvey, 2015). Several examples of gender normativity emerged in our dataset. Fathers were especially concerned about their daughters (Salomon, Stokman). Gender normativity also emerged when sons did not fully conform to prevailing beliefs about masculinity. The 11-year-old son in the family Daniels revealed to "really like" My Little Pony: "I'm like, I want to say it but I just don't dare." The mother was concerned about her son's vulnerability if he shared this online. The son also thought very carefully with whom he would dare to share this online.

Young people manifested a lot of concern about how to protect one's reputation online, and at the same time also disdain for others who, according to them, were too careless with their privacy. When we asked them to give an example, they only involved girls. The older boys in our study, such as Denny, expressed moral disapproval of girls who had published or had been exposed in seminude photos, as the following excerpt illustrates:

In first grade, during the examination period, there was some strange girl in second grade who had posted a nude picture of herself. Well, she didn't post it herself. Apparently, it was her stepsister who had done this....But you do not take nude pictures of yourself, to begin with.

The older girls, such as Charlotte, growing up with her single mother, demonstrated a great sensitivity about which pictures would be morally questionable. In explaining to us what pictures she would never post, she clearly distanced herself from other girls who, according to her, "could do what they like," but that she "would not post beach pictures of herself in a bikini, no thanks," given that "men could see that too."

Similar examples of displaying moral superiority were also found among young children, but more in terms of "stupid children" who do not know that it is not safe to share personal details on the Internet. As found in other studies, the terminology that the children in our study used suggests that young people from dominant backgrounds who are raised in the spirit of empowerment, make themselves morally superior to weaker ones (e.g., Jorge \& Farrugia, 2017). Their ideas resonated with how parents talked about other parents, who "have not studied" and therefore "do not know how to assist their children properly" (Rani), and hence "have negative experiences with their children" (Gemma).

\section{Conclusions}

This study sought to attain a contextualised understanding of family narratives about onlife privacy. More particularly, we wanted to shed light on the nexus between children's and parents' moral accounts. We focused on the family as the prime setting for moral socialisation, including the establishment and negotiation of rules and values surrounding privacy. To this aim, we analysed the data of a focused ethnographic study with 10 families, organised along two axes: (1) the three dimensions of privacy (self-ego; environmental; and interpersonal) and (2) the quadruple $\mathrm{R}$ principles (risk, responsibility, reputation, and respect for privacy). The integration was helpful to understand the complexity of family life; it invited us to be attentive to the different dimensions of privacy and myriad moral meanings surrounding it.

There are several limitations to this research. First, although every family and every situation were different, they all were from "dominant backgrounds" (Livingstone \& Blum-Ross, 2019), with high financial resources and/or cultural resources and therefore sharing a keen interest in the importance of digital technologies in society. Acknowledging the limitation of only shedding light on this particular social milieu, this study nevertheless contributes to a more in-depth understanding of how dominant narratives on digital media and privacy in western society, circulating in the media, education and policy milieus, are (re)produced in privileged family circles. Against our expectations, given their affinity with digital media, high cultural capital and open-mindedness, the parents in our study mobilised stories on stranger danger, sexual predators, and cyberbullying to explain their practices and attitudes regarding their children's online privacy. Although research has found that liberal parents, as in our study, adopt a more nuanced and critical stance towards moral panics on children (boyd \& Hargittai, 2013), we found that even self-confident parents with advanced media proficiency construct their moral narratives within the wider cultural discourses on media and their risks for children. What is more, both parents and their children seemed to rely on these nar- 
ratives to morally distance from "naïve" and "ignorant" others who failed to handle their onlife privacy properly, despite all the information circulating on the risks of the Internet.

We are also mindful of the fact that, given the ethnographic approach, the study remained necessarily smallscale, impeding us from drawing generalising conclusions for Flemish middle-class families. Finally, the fact that the data go some years back in time, we were not able to touch on more recent developments in technology use, such as online tracking devices, and its potential impact on the rapport between parents and children regarding privacy.

However, in agreement with the underpinning idea of Wolfe's et al. framework and research on cultural imageries (Leick, 2019), we would argue that culture and the dominant perspectives of the community, to which media narratives are inherent, is a robust environmental element that plays "a decisive role in the way an individual defines privacy situations" (Laufer \& Wolfe, 1977, p. 28). Hence, together with recent studies, we found that the children in our study were brought up with solid moral principles that revolve around risk, responsibility, and reputation. First, the shadow of the risk society returned in both the parents' and children's narratives. In that connection, the stranger danger mantra came in easily, often based on (news) stories they had heard. Second, parents allowed their maturing children considerable privacy. They gradually maintained more distance and gave increased trust, while stimulating selfreliance. This is compatible with generally accepted ideas about healthy moral development, i.e., to guide children towards autonomy and self-reliance. At the same time, parents also saw it as their children's task to protect their personal and the family's privacy, as they had taught them the rules. Third, reputation mainly came to the surface in the children's experiences. Concerned about the detrimental effects that disclosing pictures or details might have on their image among peers, emergent teenagers were watchful and voiced their discontent vis-à-vis their parents when they had shared an "embarrassing" picture of their children online.

In conclusion, however, we found that respect for privacy is the decisive principle around which both parents and emergent teenagers understand onlife privacy within the family circle. Obviously, privacy-related incidents in family life were reported, but what stuck out is that these incidents were fiercely discussed, indicating that transgressing privacy rules inside the family was something one had to account for. As one of the strongest repeated motifs in the families' narratives, all parents agreed that good parenting is built on giving trust and autonomy to the maturing child and respecting his or her privacy.

\section{Acknowledgments}

The PhD research, on which this article builds, was funded by the Flemish Research Organization (FWO).
We would like to thank the families who participated in this study and also to express our gratitude to the reviewers for their useful comments.

\section{Conflict of Interests}

The authors declare no conflict of interests.

\section{References}

Adorjan, M., \& Ricciardelli, R. (2019). A new privacy paradox? Youth agentic practices of privacy management despite "nothing to hide" online. Canadian Review of Sociology, 56(1). https://doi.org/10.1111/ cars. 12227

Autenrieth, U. (2018). Family photography in a networked age: Anti-sharenting as a reaction to risk assessment and behaviour adaptation. In G. Mascheroni, C. Ponte, \& A. Jorge (Eds.), Digital parenting: The challenges for families in the digital age (pp. 219-232). Gothenburg: The International Clearinghouse on Children, Youth and Media \& Nordicom.

Balleys, C., \& Coll, S. (2017). Being publicly intimate: Teenagers managing online privacy. Media, Culture \& Society, 39(6), 885-901.

Berriman, L., \& Thomson, R. (2014). Spectacles of intimacy? Mapping the moral landscape of teenage social media. Journal of Youth Studies, 18(5), 583-587.

Blum-Ross, A., \& Livingstone, S. (2017). Sharenting: Parent blogging and the boundaries of the digital self. Popular Communication, 15(2), 110-125.

boyd, d. (2014). It's complicated: The social lives of networked teens. New Haven, CT: Yale University Press.

boyd, d., \& Hargittai, E. (2013). Connected and concerned: Variation in parents' online safety concerns. Policy \& Internet, 5(3), 245-269.

Bryman, A. (2012). Social research methods. Oxford: Oxford University Press.

Burkell, J. (2016). Remembering me: Big data, individual identity and the psychological necessity of forgetting. Ethics and Information Technology, 18(1), 17-23.

Clark, S. L. (2013). The parent app: Understanding families in the digital age. Oxford: Oxford University Press.

De Wolf, R., \& Joye, S. (2019). Control responsibility: The discursive construction of privacy, teens, and Facebook in Flemish newspapers. International Journal of Communication, 13, 5505-5524.

Drotner, K. (2013). The co-construction of media and childhood. In D. Lemish (Ed.), The Routledge international handbook of children, adolescents and media (pp. 15-22). Abingdon: Routledge.

Flores, A., \& James, C. (2013). Morality and ethics behind the screen: Young people's perspectives on digital life. New Media \& Society, 15(6), 834-852.

Frankel, S. (2012). Children, morality and society. Basingstoke: Palgrave MacMillan.

Girsh, Y. (2014). The (late?) modern family: The family's 
significance for adolescents in Germany and Israel. Journal of Adolescence, 37, 863-870.

Haidt, J. (2003). The moral emotions. In R. J. Davidson, K. R. Schere, \& H. H. Goldsmith (Eds.), Handbook of affective sciences (pp. 852-870). Oxford: Oxford University Press.

Hitlin, S., \& Vaisey, S. (Eds.). (2010). Handbook of the sociology of morality. New York, NY: Springer.

Jorge, A., \& Farrugia, L. (2017). Are victims to blame? Youth, gender and moral discourse on online risk. Catalan Journal of Communication \& Cultural Studies, 9(2), 285-301.

Kaare, B. H., Brandtzaeg, P. B., Heim, J., \& Endestad, T. (2007). In the borderland between family orientation and peer culture: The use of communication technologies among Norwegian tweens. New Media \& Society, 9(4), 603-624.

Knoblauch, H. (2005). Focused ethnography. Forum Qualitative Sozialforschung/Forum: Qualitative Social Research, 6(3), Art. 44. Retrieved from https:// www.qualitative-research.net/index.php/fqs/article/ view $/ 20 / 43$

Koops, B. K. (2018). Privacy spaces. West Virginia University Law Review, 121(2), 612-665.

Laufer, R. S., \& Wolfe, M. (1977). Privacy as a concept and a social issue: A multidimensional developmental theory. Journal of Social Issues, 3(3), 22-42.

Leick, K. (2019). Parents, media and panic through the years: Kids those days. Cham: Palgrave Pivot.

Livingstone, S., \& Blum-Ross, A. (2019). Parents' role in supporting, brokering or impeding their children's connected learning and media literacy. Cultural Science Journal, 11(1), 68-77.

Livingstone, S., \& Sefton-Green, J. (2016). The class: Living and learning in the digital age. New York, NY: New York University Press.

Lupton, D., \& Williamson, B. (2017). The datafied child: The dataveillance of children and implications for their rights. New Media \& Society, 19(5), 780-794.

Montreuil, M., Noronha, C., Floriani, N., \& Carnevale, F. (2018). Children's moral agency: An interdisciplinary scoping review. Journal of Childhood Studies, 43(2), 17-30.

Mostmans, L. (2017). Under the radar: Preadolescents' moral conceptions about online self-disclosure (Unpublished doctoral thesis). Vrije Universiteit Brussel, Brussels, Belgium.

Mostmans, L., Bauwens, J., \& Pierson, J. (2014). "I would never post that": Children, moral sensitivity and online disclosure. Communications, 39(3), 347-367.

Naab, T. (2018). From media trusteeship to parental mediation: The parental development of parental mediation. In G. Mascheroni, C. Ponte, \& A. Jorge
(Eds.), Digital parenting: The challenges for families in the digital age (pp. 93-102). Gothenburg: The International Clearinghouse on Children, Youth and Media \& Nordicom.

Ochs, E., \& Kremer-Sadlik, T. (2007). Introduction: Morality as family practice. Discourse \& Society, 18(1), 5-10.

Ortner, C., \& Holly, S. (2019). A question of commitment, attention and trust: The role of smartphone practices for parent-child relationships in adolescence. Kommunikation.medien: Open-AccessJournal für den wissenschaftlichen Nachwuchs, 10. https://doi.org/10.25598/jkm/2019-10.8

Pangrazio, L., \& Cardozo Gaibisso, L. (2020). Beyond cybersafety: The need to develop social media literacies in pre-teens. Digital Education Review, 37, 49-63.

Pasupathi, M., \& Wainryb, C. (2010). Developing moral agency through narrative. Human Development, 53, 55-80.

Paus-Hasebrink, I., Kulterer, J., \& Sinner, P. (2019). Social inequality, childhood and the media: A longitudinal study of the mediatization of socialisation. London: Palgrave Macmillan.

Ringrose, J., \& Harvey, L. (2015). Boobs, pack-off, six packs and bits: Mediated body parts, gendered reward, and sexual shame in teens' sexting images. Continuum: Journal of Media \& Cultural Studies, 29(2), 205-217.

Steinberg, L. D., \& Silk, J. S. (2002). Parenting adolescents. In M. Bornstein (Ed.), Handbook of parenting (Vol 1, pp. 103-133). Mahwah, NJ: Erlbaum.

Sterponi, L. (2003). Account episodes in family discourse: The making of morality in everyday interaction. Discourse Studies, 5(1), 79-100.

United Nations General Assembly. (1989). Convention on the rights of the child. In Treaty series (Vol. 1577, p. 3). New York, NY: UN General Assembly. Retrieved from https://treaties.un.org/pages/View Details.aspx?src=IND\&mtdsg_no=IV-11\&chapter $=4$ \&lang=en

Wolfe, M. (1978). Childhood and privacy. In I. Altman \& J. F. Wohlwill (Eds.), Children and the environment (pp. 175-222). New York, NY: Plenum Press.

Zarouali, B., Poels, K., Walrave, M., \& Ponnet, K. (2019). The impact of regulatory focus on adolescents' evaluation of targeted advertising on social networking sites. International Journal of Advertising, 38(2), 316-335.

Zimmer-Gembeck, M. J., \& Collins, W. A. (2003). Autonomy development during adolescence. In G. R. Adams \& M. Berzonsky (Eds.), Blackwell handbook of adolescence (pp. 175-204). Oxford: Blackwell Publishers. 


\section{About the Authors}
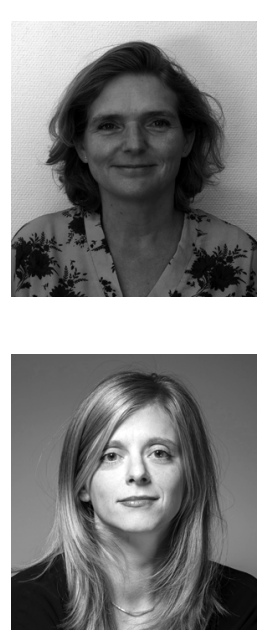

Katleen Gabriels is a Moral Philosopher, specialised in Computer and Machine Ethics. She is an Assistant Professor at Maastricht University (the Netherlands), where she is also the Program Director of the BA Digital Society. She is an Executive Board Member of INSEIT, Steering Committee Member and the Deputy Chair of ETHICOMP and an Affiliate Member of 4TU Centre for Ethics and Technology. She is the Author of Regels voor robots (2019, VUBPRESS; the English version, Conscientious Al: Machine(s) Learning Morals, is forthcoming in 2020).

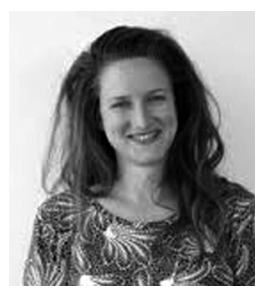

Lien Mostmans holds a PhD in Media and Communication Studies, obtained in 2017 at Vrije Universiteit Brussels, Belgium. She has extensive research experience in the field of children and media cultures, using a wide range of qualitative (ethnographic, visual) methodologies. Since 2018, she has been working as Research Advisor for Erasmus Brussels University of Applied Sciences and Arts, Belgium, where she coordinates international research projects in the fields of children, education, and healthcare. 